University of South Carolina

Scholar Commons

2013

\title{
An Acid Catalyzed Reversible Ring-Opening/Ring-Closure Reaction Involving a Cyano-Rhodamine Spirolactam
}

H. Li

H. Guan

X. Duan

J. Hu

Guiren Wang

University of South Carolina - Columbia, wanggu@cec.sc.edu

See next page for additional authors

Follow this and additional works at: https://scholarcommons.sc.edu/emec_facpub

Part of the Biochemistry Commons, Molecular Biology Commons, and the Organic Chemistry

\section{Commons}

\section{Publication Info}

Published in Organic \& Biomolecular Chemistry, Volume 11, Issue 11, 2013, pages 1805-1809.

(C) Organic \& Biomolecular Chemistry 2013, Royal Society of Chemistry

Li, H., Guan, H., Duan, X., Hu, J., Wang, G., \& Wang, Q. (2013). An acid catalyzed reversible ring-opening/

ring-closure reaction involving a cyano-rhodamine spirolactam. Organic \& Biomolecular Chemistry, 11(11), 1805-1809.

http://dx.doi.org/10.1039/С30B27356C

This Article is brought to you by the Mechanical Engineering, Department of at Scholar Commons. It has been accepted for inclusion in Faculty Publications by an authorized administrator of Scholar Commons. For more information, please contact digres@mailbox.sc.edu. 


\section{Author(s)}

H. Li, H. Guan, X. Duan, J. Hu, Guiren Wang, and Qian Wang 


\section{Organic \& \\ Biomolecular Chemistry}

RSCPublishing

\section{COMMUNICATION}

Cite this: Org. Biomol. Chem., 2013, 11, 1805

Received 4th December 2012,

Accepted 18th January 2013

DOI: $10.1039 / c 30 b 27356 c$

www.rsc.org/obc

Cyanamide was introduced into the rhodamine spirolactam framework to produce a colorless and non-fluorescent compound $\mathrm{RBCN}$. It shows a reversible ring-opening/ring-closure process in response to the solution $\mathrm{pH}$, which exhibits an "ON/OFF" switching in its fluorescence. Different from other rhodamine-type dyes, the ring-open form of $\mathrm{RBCN}$ is stable in protic solvents under neutral, near neutral and basic conditions, showing a pink color and very strong fluorescence. We also demonstrated the potential of RBCN in live cell imaging.

Chromogenic and fluorogenic signaling sensors for the detection and measurement of target analytes have been widely investigated in many areas such as biochemistry, ${ }^{1 a, b}$ medical diagnosis, ${ }^{1 c}$ and environmental analysis. ${ }^{1 d}$ The chromogenic signaling module can easily offer naked eye detection by color changes while the fluorescent methods can give high sensitivity and shorter response time, and thus can offer a real-time monitoring of a process occurring at different time scales. Hence, sensors of this kind have attracted enormous interest in the past decade. ${ }^{1 a, e}$

The rhodamine based dyes have recently been extensively used for molecular recognition and molecular devices ${ }^{2 a}$ due to their excellent photophysical properties, such as high extinction coefficients, excellent quantum yields, great photostability, and relatively long emission wavelengths. The well-known rhodamine spirolactam framework is an ideal system to construct OFF-ON sensors because the ring closed spirolactam form is non-fluorescent and colorless while the corresponding ring open form is strongly fluorescent and pink colored. ${ }^{2}$ It is convenient to introduce the demanded recognition site into the spirolactam system and develop it as the dual channel

\footnotetext{
${ }^{a}$ Department of Chemistry and Biochemistry, University of South Carolina, 631 Sumter Street, Columbia, SC 29208, USA. E-mail: wang263@mailbox.sc.edu ${ }^{b}$ Department of Mechanical Engineering and Biomedical Engineering Program, University of South Carolina, 631 Sumter Street, Columbia, SC 29208, USA †Electronic supplementary information (ESI) available: X-ray structural data, synthesis and structural proofs data, additional spectroscopic data and graph are provided. CCDC 913590. For ESI and crystallographic data in CIF or other electronic format see DOI: $10.1039 / \mathrm{c} 3 \mathrm{ob} 27356 \mathrm{c}$
}

(chromogenic and fluorogenic) OFF-ON sensor for detection of various analytes such as transition and heavy metal ions, ${ }^{3}$ anions, ${ }^{4}$ amino acids ${ }^{5}$ and reactive oxygen species. ${ }^{6}$

The commonly existing form of the rhodamine spirolactam derivative is colorless and non-fluorescent in common (protic or aprotic) solvents, which structurally equilibrates to a colored and highly fluorescent ring-opened amide form upon analyteinduced binding or reaction. ${ }^{2}$ For example, an acidic $\mathrm{pH}$ can usually activate a non-fluorescent rhodamine spirolactam to be a highly fluorescent rhodamine derivative (Scheme 1). In the literature, this kind of spirolactam ring was usually formed by condensation with an aliphatic or aromatic amine, hydrazine or hydrazone that linked with a variety of receptors. ${ }^{2}$ In our study, a strong electron withdrawing group, the cyano group which has quite different electronic properties compared with that in the literature, was introduced into the spirolactam framework. Since the strong electron withdrawing effect of the cyano group can stabilize the cyanamide anion both inductively and by resonance delocalization (Scheme 2), ${ }^{7}$

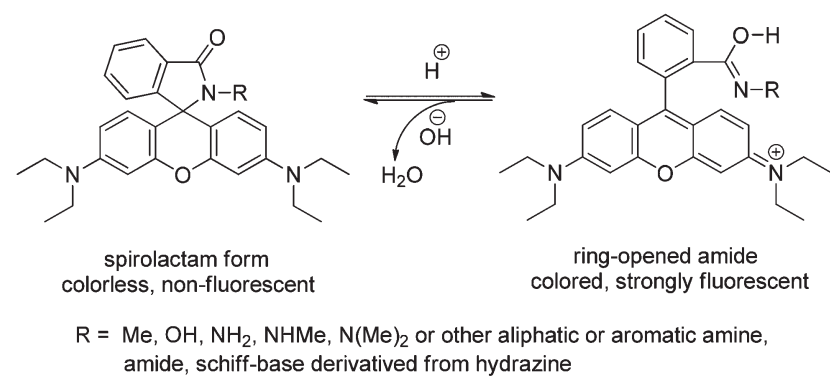

Scheme 1 The reversible process of the rhodamine derivative controlled by $\mathrm{pH}$. The acidic condition can result in the transition from spirolactam to ringopened amide.

$$
\mathrm{HN}-\stackrel{\ominus}{\mathrm{C}} \equiv \mathrm{N} \longleftrightarrow \mathrm{HN}=\mathrm{C}=\stackrel{\ominus}{\stackrel{N}{ }}
$$

Scheme 2 Resonance delocalization of the cyanamide anion. 
the introduction of cyanamide would thus result in very different fluorogenic properties for RBCN.

The compound RBCN was easily synthesized by condensation of the commercially available rhodamine B and cyanamide in refluxed ethanol solution (Scheme 3) with a moderate yield of $55 \%$. Its structure was confirmed by ${ }^{1} \mathrm{H}-\mathrm{NMR}$, ${ }^{13} \mathrm{C}-\mathrm{NMR}$, and MS analysis. The X-ray crystal structure ${ }^{8}$ (see Table S1 and Fig. S1 $\uparrow$ for details) clearly represents the unique spirolactam ring structure (Fig. 1), which is also supported by the characteristic peak near 69.3 ppm (spiro-carbon) in the
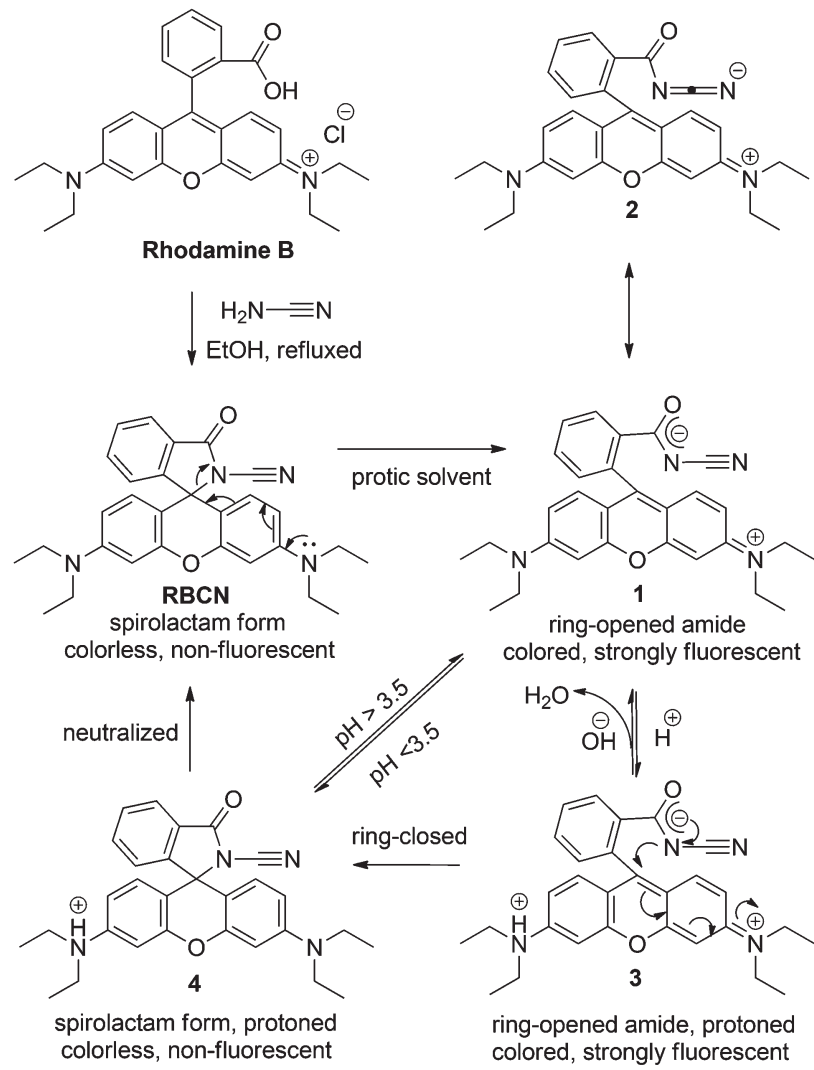

Scheme 3 Synthesis of $\mathbf{R B C N}$ and the proposed mechanism for the acid catalyzed ring-opening/ring-closure process.

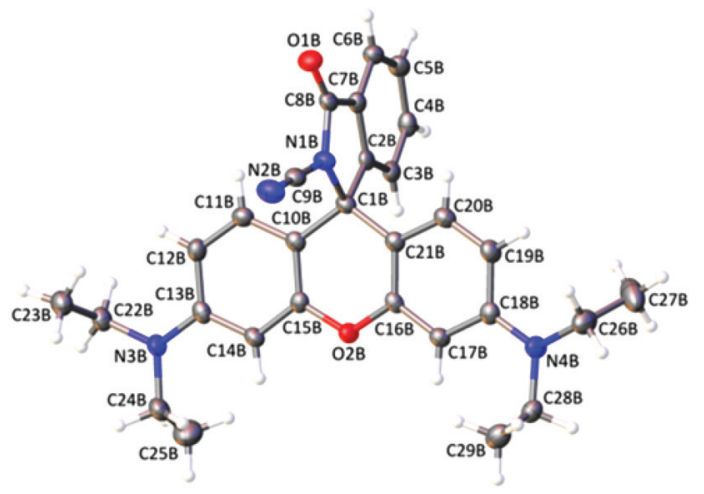

Fig. 1 X-ray crystal structure of RBCN. Displacement ellipsoids are shown at the $50 \%$ probability level.
${ }^{13} \mathrm{C}-\mathrm{NMR}$ spectra of $\mathbf{R B C N}$ in $\mathrm{CDCl}_{3}$. The absorption spectrum of RBCN in different solvents (Fig. S2 $\dagger$ ) shows that there are evident absorption peaks in the protic solvents (pink color, Fig. S3†), such as $\mathrm{MeOH}$ (peak at $548 \mathrm{~nm}$ ), EtOH (peak at $547 \mathrm{~nm}$ ) and $\mathrm{H}_{2} \mathrm{O}$ (peak at $558 \mathrm{~nm}$ ), but no evident absorption peaks in the aprotic solvents. As shown in Fig. 2, similar results can also be observed from the fluorescence spectra. RBCN in protic solvents displays a strong emission (orange fluorescence) at $572 \mathrm{~nm}$ in $\mathrm{MeOH}, 569 \mathrm{~nm}$ in $\mathrm{EtOH}$ and $583 \mathrm{~nm}$ in $\mathrm{H}_{2} \mathrm{O}$ and no evident emission peaks were observed in aprotic solvents. Both the absorption and emission properties confirm that RBCN exists as a ring-open amide in these protic solvents (for RBCN in other protic solvents, see photos in Fig. S3†).

As references reported, all the rhodamine spirolactam derivatives are colorless and non-fluorescent in common (protic or aprotic) solvents and then will act as chromogenic and fluorogenic sensors in the target analytes sensing process. $^{2}$ Only Bag's group developed a FRET signaling system based on rhodamine $\mathrm{B}$ and nitrobenzofurazan fluorophores with an acyclic amino receptor, ${ }^{9}$ that will display a prominent enhancement in absorption and emission induced by $\mathrm{H}_{2} \mathrm{O}$, $\mathrm{MeOH}$ or EtOH. They pointed out that the H-bonding interactions ${ }^{10}$ of these protic solvents with the acyclic amino receptor might play a vital role in the ring-open process. In the case of RBCN, three points should be noticed: (a) the strong polarity of these solvents is favorable for the intramolecular charge separation in its ring-open state, (b) the ring-open amide was stabilized by the strong electron withdrawing cyano group, and (c) potential H-bonding interactions of the protic solvents with the cyanamide moiety ${ }^{7 d}$ may also contribute to stability of the ring-open state.

Although there was very weak fluorescence for $\mathbf{R B C N}$ in aprotic solvents such as acetone, $\mathrm{CH}_{3} \mathrm{CN}$, THF, DMF and DMSO, the trace amounts of water can lead to an evident fluorescence enhancement (Fig. S4†). This can be even detected by the naked eye under UV-light (Fig. S4b† inset). It is well known that rhodamine spirolactam derivatives can act as fluorescent sensors for $\mathrm{pH}$ sensing under acidic conditions due to the ring-open process induced by the proton (Scheme 1). ${ }^{11}$

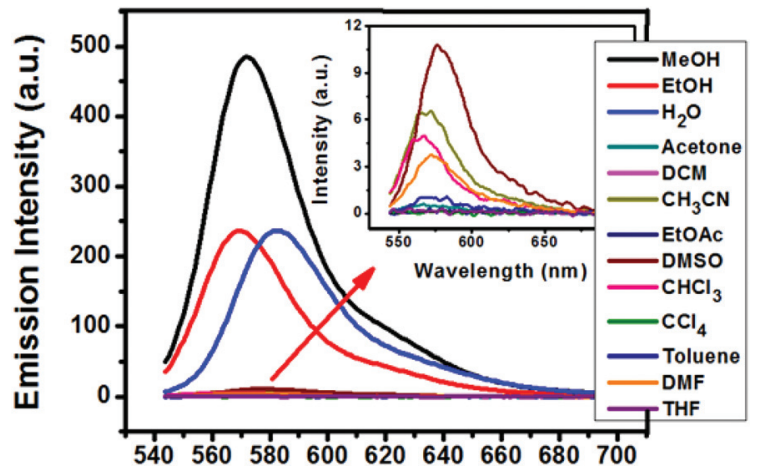

Fig. 2 Fluorescence spectrum of $\mathbf{R B C N}(10 \mu \mathrm{M})$ in different solvents. $\lambda_{\text {ex }}=$ $530 \mathrm{~nm}$. 
However, in our RBCN system, the cyano group makes it display very different spectroscopic properties under acidic conditions as compared with similar rhodamine spirolactam compounds. RBCN was strongly fluorescent in the basic, neutral and near-neutral range as shown in a $\mathrm{pH}$ titration experiment (Fig. 3c). When the $\mathrm{pH}$ was decreased below 3.5, the fluorescence decreased and was completely quenched at $\mathrm{pH} \sim 1.2$, accompanied by similar changes of absorption intensity. Fig. 3 displays the absorption (Fig. 3a) and fluorescence (Fig. 3b) spectrum changes of RBCN from $\mathrm{pH} 1.2$ to 4.2. These results show an inversed pattern of $\mathrm{pH}$-dependent
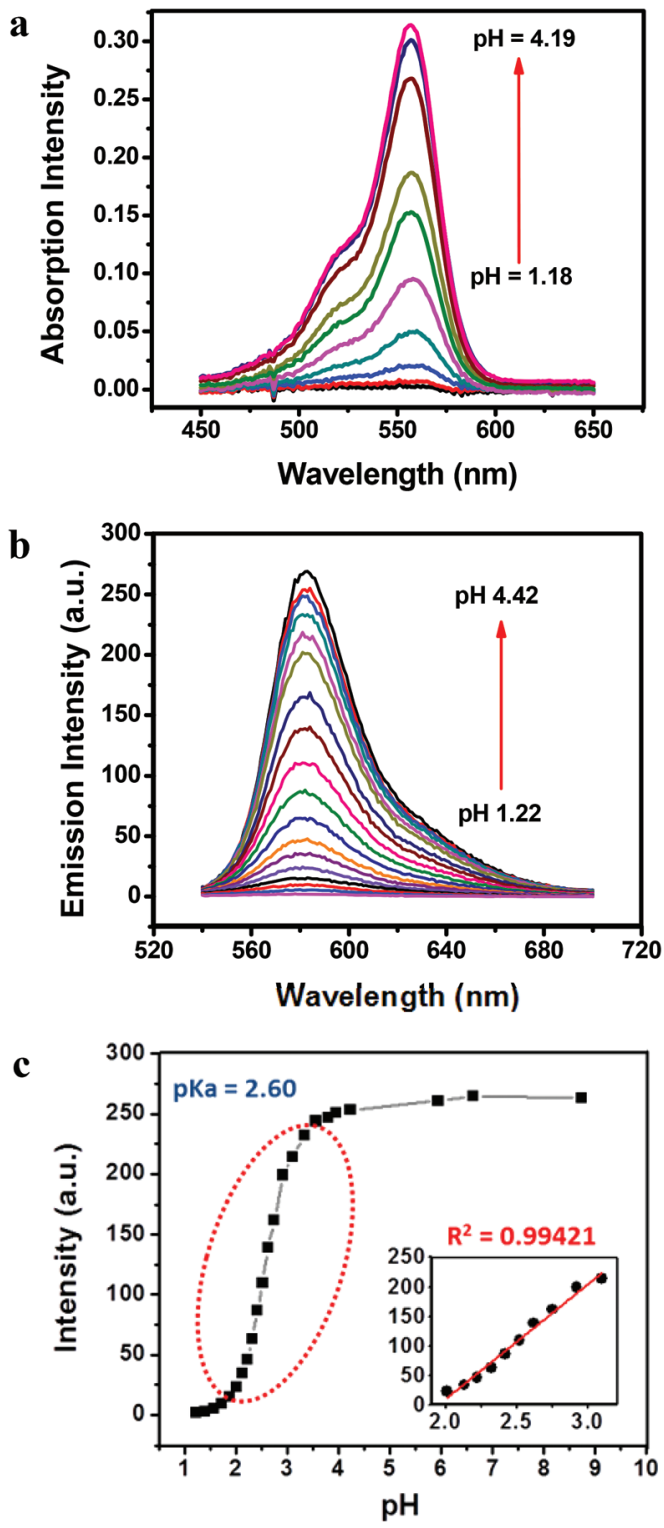

Fig. 3 The absorption (a), fluorescence (b) spectral changes and fluorescence intensity (at $583 \mathrm{~nm}$ ) changes (c) of RBCN under different $\mathrm{pH}$ conditions. The inset of (c) shows the linear relationship between fluorescence intensity and $\mathrm{pH}$ from 2.0 to 3.1. Conditions: RBCN $(10 \mu \mathrm{M})$ in water with $0.2 \%$ acetonitrile. $\mathrm{pH}$ was adjusted by $0.1 \mathrm{M}$ and $2.0 \mathrm{M} \mathrm{HCl}_{(\mathrm{aq})}$ and $\mathrm{NaOH}_{(\mathrm{aq})}, \lambda_{\mathrm{ex}}=530 \mathrm{~nm}, \lambda_{\mathrm{em}}=$ $583 \mathrm{~nm}$. changes in fluorescence and absorption changes compared with the traditional rhodamine spirolactam analogs.

Recently, more efforts have been made on the development of "acidic" probes with high sensitivity, good photostability and excellent membrane permeability based on the rhodamine spirolactam framework. ${ }^{11}$ However, all of them display fluorescence decreases when $\mathrm{pH}$ was adjusted from low to high in their working range (commonly around $\mathrm{pH}$ 4.0-6.0). Herein, we developed RBCN as a sensitive fluorescence 'turn-on' sensor for detection of $\mathrm{pH}$ changes under more acidic conditions. As shown in Fig. 3c, the fluorescence signals increased when $\mathrm{pH}$ was adjusted from 1.2 to 4.0 and they were linearly correlated $\left(R^{2}=0.994\right)$ to $\mathrm{pH}$ changes from 2.0 to 3.1 (Fig. $3 \mathrm{c}$ inset).

Additionally, the pH-dependent change in the fluorescence and absorption of $\mathbf{R B C N}$ is reversible and can be repeated for multiple cycles (Fig. 4). We also used NMR spectra to monitor the ring-opening/ring-closure process involving RBCN (Fig. S5 and $\mathrm{S}^{+}$). The characteristic peak at $69.3 \mathrm{ppm}$ in ${ }^{13} \mathrm{C}-\mathrm{NMR}$ is ascribed to the signal of the spiro-carbon atom which demonstrated the ring-closed form of $\mathbf{R B C N}$ in $\mathrm{CDCl}_{3}$. When $\mathrm{CD}_{3} \mathrm{OD}$ was added into this sample, the peak for the spiro-carbon atom disappeared and shifted to $143.7 \mathrm{ppm}$, with the color changing from light pink to red which indicated the ring-open form of RBCN. After adding $16.7 \%(\mathrm{v} / \mathrm{v})$ of $\mathrm{DCl}^{12}$ and mixing well, the light pink color of the RBCN sample was immediately recovered. Moreover, the peak at $143.7 \mathrm{ppm}$ shifted back to the alkyl region on the ${ }^{13} \mathrm{C}-\mathrm{NMR}$ spectrum around $67.2 \mathrm{ppm}$. The recovery of spiro-carbon is a strong support for the ringclosure of RBCN.

We then proposed an acid catalyzed reversible ringopening/ring-closure process for RBCN in a protic solvent. As shown in Scheme 3, the resonance structures (1 and 2) and the $\mathrm{H}$-bonding interaction from the protic solvent can stabilize the ring-open state of RBCN even under basic conditions. When $\mathrm{pH}$ was decreased to lower than 3.5, the H-bonding interaction was effectively quenched by the increasing of $\mathrm{H}^{+}$and the $\mathrm{N}$-cyano amide moiety was free. It displayed lower basicity but better nucleophilicity ${ }^{7}$ (compared with amides in other similar

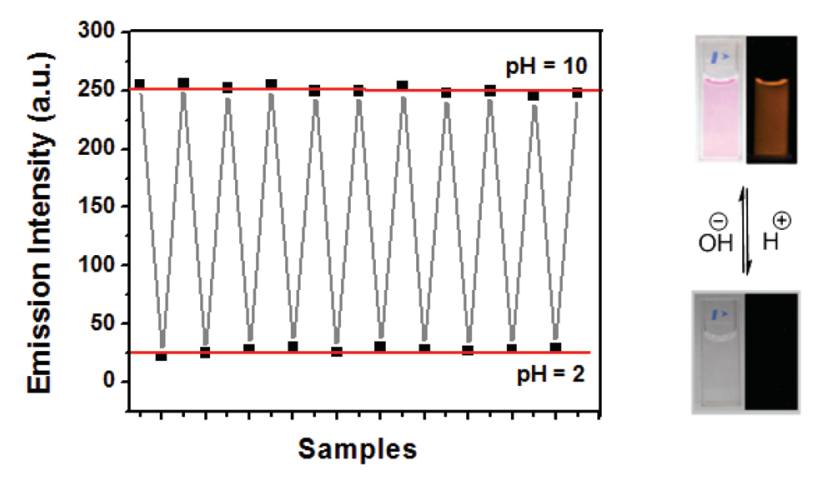

Fig. 4 The reversible pH-dependent fluorescence changes (left) and photos (right) of RBCN. Conditions: $10 \mu \mathrm{M}$ of RBCN in water with $0.2 \%$ acetonitrile at $\mathrm{pH}=2$ and 10. The $\mathrm{pH}$ was adjusted by $\mathrm{HCl}_{(\mathrm{aq})}$ and $\mathrm{NaOH}_{(\mathrm{aq})} \cdot \lambda_{\mathrm{ex}}=530 \mathrm{~nm}, \lambda_{\mathrm{em}}$ $=583 \mathrm{~nm}$. 
rhodamine spirolactam compounds) that is favorable for the ring-closure reaction. Additionally, the diethylamino group was possibly protonated to form 3 and the electron-deficient nature of the xanthene moiety was also favorable for the nucleophilic attraction of the cyanamide moiety, thus inducing the ring-closed reaction to form the protonated $\mathbf{4}$, which can be neutralized to give the initial RBCN. Since the protonation of 3 and 4 can be easily removed by adjustment of $\mathrm{pH}$ to higher than 3.5 and generates the ring-open form $\mathbf{1}$, the acid catalyzed ring-closure process of RBCN is reversible. The peak for methylene carbon and peaks for protons on the xanthene framework (Fig. S5c and S6c $\dagger$ ) all displayed evident downfield shifts that supported the protonation of ring-closed RBCN.

Finally, we applied RBCN to the SW620 cell (human colon cancer cell line) to examine whether it can work for cell staining. SW620 cells were washed with PBS buffer and costained with RBCN and LysoTracker Green (LysoTracker Green DND-26) or MitoTracker Green (MitoTracker Green FM) from Invitrogen. The cells imaging was taken by confocal fluorescence microscopy to probe the distribution of $\mathbf{R B C N}$ relative to LysoTracker Green (Fig. 5 top) or MitoTracker Green (Fig. 5 bottom) in live cells. The co-staining experiments revealed that RBCN mostly stained the lysosomes, exhibiting staining patterns that were nearly identical to that of LysoTracker Green (Fig. 5 top). The colocalization of RBCN with LysoTracker Green, instead of MitoTracker Green, suggested that RBCN displayed a better selectivity for lysosomes compared with mitochondria in live cells, which is consistent with literature reports that rhodamine spirolactam based sensors prefer lysosome in live cells. ${ }^{11 b, c}$

In summary, we presented the synthesis of RBCN, a new rhodamine spirolactam derivative with a cyano group. The strong electron withdrawing group makes RBCN display much different spectral properties as compared with other reported similar rhodamine spirolactams. In protic solvents, RBCN exists as a ring-open state under neutral, near neutral and
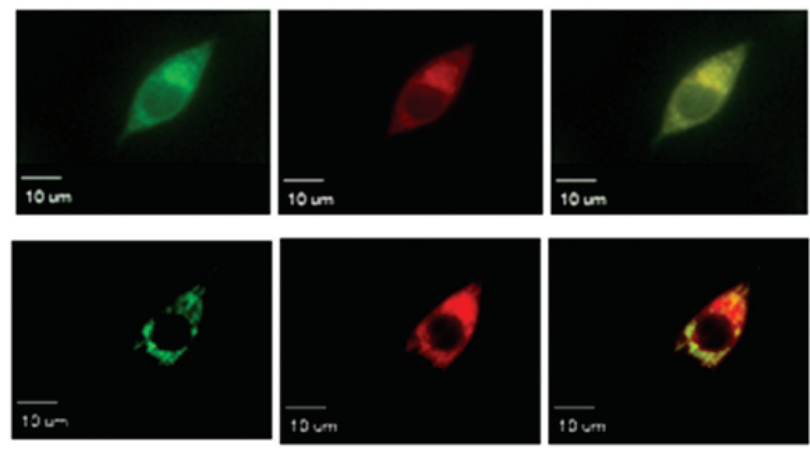

Fig. 5 Intracellular distribution of RBCN as compared to LysoTracker Green or MitoTracker Green. SW620 cells were co-stained with LysoTracker Green and RBCN (top) or MitoTracker Green and RBCN (bottom). Green fluorescence shows the localization of LysoTracker Green or MitoTracker Green while red fluorescence indicates the localization pattern of RBCN. Merging of the fluorescence of LysoTracker Green or MitoTracker Green and RBCN was shown in yellow. Concentration: $5 \mu \mathrm{M}$ for RBCN, $15 \mathrm{nM}$ for LysoTracker Green and $500 \mathrm{nM}$ for MitoTracker Green, respectively. Scale bars are $10 \mu \mathrm{m}$. basic conditions. From the $\mathrm{pH}$ titration experiment, RBCN shows an acid catalyzed reversible ring-opening/ring-closure process in aqueous solution. To the best of our knowledge, this is the first report about the acid catalyzed ring-opening/ ring-closure involving rhodamine spirolactam derivatives. Finally, we also demonstrated that RBCN displayed a better selectivity for lysosomes compared with mitochondria in live cells.

\section{Acknowledgements}

This work was partially supported by the US NSF MRI-1040227 and the Camille Dreyfus Teacher Scholar Award.

\section{Notes and references}

1 (a) J. S. Kim and D. T. Quang, Chem. Rev., 2007, 107, 3780; (b) S.-K. Ko, X. Chen, J. Yoon and I. Shin, Chem. Soc. Rev., 2011, 40, 2120; (c) A. T. Wright and E. V. Anslyn, Chem. Soc. Rev., 2006, 35, 14; (d) A. P. de Silva, H. Q. N. Gunaratne, T. Gunnlaugsson, A. J. M. Huxley, C. P. McCoy, J. T. Rademacher and T. E. Rice, Chem. Rev., 1997, 97, 1515; (e) R. Martínez-Mánez and F. Sancenòn, Chem. Rev., 2003, 103, 4419.

2 (a) X. Chen, T. Pradhan, F. Wang, J. S. Kim and J. Yoon, Chem. Rev., 2012, 112, 1910; (b) M. Beija, C. A. M. Afonso and J. M. G. Martinho, Chem. Soc. Rev., 2009, 38, 2410; (c) H. N. Kim, M. H. Lee, H. J. Kim, J. S. Kim and J. Yoon, Chem. Soc. Rev., 2008, 37, 1465.

3 Recent examples: (a) J. Zhang, Y. Zhou, J. Yoon, Y. Kim, S. J. Kim and J. S. Kim, Org. Lett., 2010, 12, 3852; (b) M. E. Jun and K. H. Ahn, Org. Lett., 2010, 12, 2790; (c) H. Li, J. Fan, J. Du, K. Guo, S. Sun, X. Liu and X. Peng, Chem. Commun., 2010, 46, 1079; (d) H. Li, J. Fan, F. Song, H. Zhu, J. Du, S. Sun and X. Peng, Chem.-Eur. J., 2010, 16, 12349; (e) H. Li, J. Fan, M. Hu, G. Cheng, D. Zhou, T. Wu, F. Song, S. Sun, C. Duan and X. Peng, Chem.-Eur. J., 2012, 18, 12242; $(f)$ H. N. Kim, S.-W. Nam, K. M. K. Swamy, Y. Jin, X. Chen, Y. Kim, S.-J. Kim, S. Park and J. Yoon, Analyst, 2011, 136, 1339.

4 (a) C. R. Lohani, J.-M. Kim, S.-Y. Chung, J. Yoon and K.-H. Lee, Analyst, 2010, 135, 2079; (b) Z. Hu, X. Wang, Y. Feng, L. Ding, M. Li and C. Lin, Chem. Commun., 2011, 47, 1622 .

5 (a) Y.-K. Yang, S. Shim and J. Tae, Chem. Commun., 2010, 46, 7766; (b) H. Li, J. Fan, J. Wang, M. Tian, J. Du, S. Sun, P. Sun and X. Peng, Chem. Commun., 2009, 5904.

6 (a) X. Chen, K.-A. Lee, E.-M. Ha, K. M. Lee, Y. Y. Seo, H. K. Choi, H. N. Kim, M. J. Kim, C.-S. Cho, S. Y. Lee and W. J. Lee, Chem. Commun., 2011, 47, 4373; (b) L. Yuan, W. Lin, Y. Xie, B. Chen and S. Zhu, J. Am. Chem. Soc., 2012, 134, 1305.

7 (a) F. Cacace and G. de Petris, J. Phys. Chem., 1993, 97, 4239; (b) B. Kallies and R. Mitzner, J. Phys. Chem. B, 1997, 
101, 2959; (c) C. F. Bernasconi, A. E. Leyes and Z. Rappoport, J. Org. Chem., 1999, 64, 2897; (d) G. M. Chaban, J. Phys. Chem. A, 2004, 108, 4551.

8 The single crystal suitable for X-ray diffraction studies was grown by the evaporation of RBCN solution with the mixed solvents of $\mathrm{CH}_{2} \mathrm{Cl}_{2}$ and $\mathrm{MeOH}$ for 5 days. See ESI $\dagger$ for data details. CCDC 913590 contains the supplementary crystallographic data for this paper.

9 B. Bag and A. Pal, Org. Biomol. Chem., 2011, 9, 915.

10 (a) L. E. Cramer and K. G. Spears, J. Am. Chem. Soc., 1977, 100, 221; (b) K. G. Casey and E. L. Quitevis, J. Phys. Chem., 1988, 92, 6590.

11 (a) Q. A. Best, R. Xu, M. E. McCarroll, L. Wang and D. J. Dyer, Org. Lett., 2010, 12, 3219; (b) Z. Li, S. Wu, J. Han and S. Han, Analyst, 2011, 136, 3698; (c) S. Wu, Z. Li, J. Han and S. Han, Chem. Commun., 2011, 47, 11276; (d) N. B. Yapici, S. R. Mandalapu, T.-L. Chew, S. Khuon and L. Bi, Bioorg. Med. Chem. Lett., 2012, 22, 2440; (e) W. Zhang, B. Tang, X. Liu, Y. Liu, K. Xu, J. Ma, L. Tong and G. Yang, Analyst, 2009, 134, 367; $(f)$ V. B. Bojinov, A. I. Venkova and N. I. Georgiev, Sens. Actuators, B, 2009, 143, 42; (g) T. Hasegawa, Y. Kondo, Y. Koizumi, T. Sugiyama, A. Takeda, S. Ito and F. Hamada, Bioorg. Med. Chem., 2009, 17, 6015; (h) S. Kang, S. Kim, Y.-K. Yang, S. Bae and J. Tae, Tetrahedron Lett., 2009, 50, 2010.

12 After treatment of RBCN with DCl for 3 days, deuteration for the proton on the xanthene ring was observed. See Fig. S7 and S8 $\uparrow$ for ${ }^{1} \mathrm{H}-\mathrm{NMR}$ and MS data. 